Копытко Наталья Владимировна - кандидат филологических наук, заведующая кафедрой стилистики английского языка Минского государственного лингвистического университета, член Европейской ассоциации американских исследований, член Белорусской ассоциации преподавателей английского языка, член Международной ассоциации преподавателей английского языка как иностранного. Адрес: 220034, Республика Беларусь, г. Минск, ул. Захарова, А. 21. Тел.: +37517288-25-63. Эл. aspec: natalia-koliadko@tut.by

Kopytko Natalia Vladimirovna, Candidate of Philology, Head, Department of English Stylistics, Minsk State Linguistic University; Member, European Association for American Studies (EAAS); Member, Belarusian Association of Teachers of English (BelNATE); Member of International Asso-ciation of Teachers of English as a Foreign Language (IATEFL). Postal address: 21, Zakharova St., Minsk, the Republic of Belarus, 220034. Tel: +37517288-25-63. E-mail: nataliakoliadko@tut.by

DOI: $10.17805 /$ zpu.2021.3.17

\title{
Апофатика места, или Поиски «иного царства» в рассказе А. Грина “Сто верст по реке»
}

\author{
M. А. ДУДАРЕВА \\ РОССИЙСКИЙ УНИВЕРСИТЕТ ДРУЖБЫ НАРОДОВ
}

Апофатика русской художественной культуры составляет самый широкий объект исследования. Апофатика, древнее понятие, сегодня иррадиирует во все исследовательские гуманитарные парадигмы. Предмет статьи: способы проявления апофатической реальности в рассказе А. Грина «Сто верст по реке», а именно анализ топоса жизни и смерти.

Методология исследования: онтогерменевтический анализ художественного произведения, который направлен на высвечивание философских вопросов текста, выявление этоса жизни и смерти. Параллель с русским фольклором, волшебной сказкой оказывается продуктивной. Для русской словесной культуры характерен поиск «иного царства», о котором в начале XX в. читал лекции философ Е. Н. Трубецкой в Московском религиозном обществе памяти Вл. Соловьева, куда входили многие представители Серебряного века. На типологическом уровне также продуктивно обращение к антропософскому учению Р. Штейнера, с которым хорошо был знаком ближайший друг писателя М. Волошин, встречавшийся с философом в 1906 г. в Париже. Немецкий антропософ в своих работах дает представление об особом имагинативном сверхчувственном восприятии действительности, которым обладают главные герои рассказа Грина.

Полученные выводы в ходе онтогерменевтического анализа могут быть полезны как культурологам, философам, интересующимся проблемами философии культуры, так и филологам, поскольку вносят уточнения в философскую концепцию жизни - смерти в русском варианте логоцентризма. В связи с этим данная методология, разрабатываемая в русской школе в трудах филолога и культуролога В. П. Океанского, может быть успешно применена и к другим художественным произведениям, в которых реализуется танатологический дискурс.

Ключевые слова: апофатика; русская сказка; традиционная культура; творчество А. Грина; философия Р. Штейнера; этос 


\section{ВВЕАЕНИЕ}

Современный философ М. В. Аогинова, рассуждая об апофатическом методе познания Бога, Начала и Безначальности, указывает на разницу между богословской и философской апофатикой: «В философской апофатике есть таинство преодоления невозможного» (Иогинова, 2003: 229). Конечно, в первую очередь в России к апофатике обратились философы и художники слова, которые на интуитивном уровне ощущали «неотмирность», инобытийность отечественного самосознания. Г. А. Тульчинский указывает на особый апофатизм русского духовного опыта: «Содержанию российской смысловой картины мира свойственна апофатическая ориентация не столько на опыт реальной жизни в этом мире, включая конструктивную трудовую деятельность, сколько на опыт переживания сопричастности трансцендентному, выходящему за рамки повседневности, иногда даже отрицания ее» (Тульчинский, 2020: 42). Но и в художественной апофатике, выраженной и визуально, и вербально, есть также способ преодоления невозможного. Бесконечно приближаться к непроговариваемому может не только философия, но и литература в русском варианте логоцентризма - и в первую очередь через размышления о смерти, поскольку она априори непостижима, любой разговор о ней начинается с отрицания. Апофатика - непостижимое в культуре, которое существовало всегда в качестве априорного условия существования сакрального космоса культуры, бытия. Однако чем дальше идет человек по пути метафизической отрешенности, отдаляясь от трансцендентного отношения к бытию, тем сильнее проявляется апофатическое начало в культуре. Ярким примером этого является отношение человечества к смерти и то, как менялось восприятие смерти. Филип Арьес в своей известной работе «Человек перед лицом смерти» описывает изменения в восприятии смерти - от прирученной смерти к смерти дальней: «Человек Нового времени начинает испытывать отстраненность от момента физической смерти... Сама же жизнь становится теперь полной, густой и протяжной, “без швов”, без перерывов, тогда как смерть, по-прежнему присутствующая в жизни, сохраняет свое место лишь на ее дальнем конце, легко забываемая, несмотря на весь реализм “Ауховных упражнений”» (Арьес, 1992: 273). Таким образом, разговор о танатологическом дискурсе культуры подводит нас к проблеме апофатического в культуре, к взаимосвязи сакрального и мирского, которая была важна особенно для архаических представлений о мире. Это означает, что проблема апофатики, выйдя из теологического лона, иррадиирует сегодня во все области научного гуманитарного знания. Вопросы апофатики культуры, которая проявляется и постигается через разные культурные феномены, в первую очередь через феномен смерти, все больше волнуют исследователей: философов (Варава, 2013; Гуревич, Спирова, 2019), филологов (Шукуров, 2006; Елепова, 2012), культурологов (Грачев, 2019; Аударева, 2020). В литературоведческих работах апофатика связывается с Абсолютами культуры, Красотой, Смертью, Аюбовью, Тишиной (Татаринова, 2011; Елепова, 2012) в высшем имагинативном их проявлении [используем понятие «имагинативный Абсолют» Я. Э. Голосовкера (Голосовкер, 2012)]. В культурологических работах с апофатической традицией связывают явление света вечернего и невечернего, мифологему вневременности (Брагинская, Шмаина-Великанова, 2013). Однако художественное бытие, авторское слово, инспирируемое в русском варианте логоцентризма и фольклорной архаической традицией, и различными философскими воззрениями на основные ценности культуры, кажется необходимым сегодня рассматривать, применяя онтогерменевтический подход к тексту, который активно развивается в совре- 
менной гуманитаристике (Океанский, 2011). Онтогерменевтика, или культурологическая поэтика, позволяет высветить «темные» места художественного текста с позиций онтологии и метафизики, которые берутся как данность культурно-исторического опыта (Океанский, 2010: 238). Обращаемся в первую очередь к русской фольклорной традиции, поскольку русский фольклор является богатым источником апофатического, связанного с оборотностью мира: «В русской речи одним из истоков возникновения средств передачи семантики невыразимого определяем фольклор с его набором устойчивых фольклорных формул ни вздумать ни взгадать, разве в сказке сказать; ни в сказке сказать, ни пером описать и др.» (Михайлова, 2017: 270; курсив источника. - М. А.). Этот формульный ряд можно продолжить фольклорными речениями из русской волшебной сказки («иду туда, не знаю куда», «ищу то, не знаю что»), связанными с поиском неведомой земли.

Творчество Грина, одного из самых загадочных авторов начала XX в. как с биографической, так и с художественной стороны, интересно не только синтезом различных методов и стилей, реалистического, романтического, но и своей онтологической глубиной, заключающейся во многом в непрекращающемся поиске пути, в движении, метафизически совпадающем с поисками новой жизни, становлением нового человека в порубежный период (Шевцова, 2003). Таким образом, объектом нашего исследования будет выступать апофатика места (этоса жизни и смерти), т. е. сакрального центра в художественном произведении, в котором соединяется реальная и космическая действительность, а предметом - способ создания апофатической реальности в рассказе А. Грина «Сто верст по реке». Под этосом вслед за М. Хайдеггером (Хайдеггер, 1993: 214-215) и В. П. Океанским в российской научной школе понимаем населенную вселенную, место пребывания, жилище (Океанский, 2011: 127).

\section{РЕКА КАК САКРААЬНЫЙ ЦЕНТР В РАССКАЗЕ}

В рассказе 1916 г. «Сто верст по реке» путь героя, по тонкому наблюдению Г. И. Шевцовой, обозначился «как переход от “тьмы странствий” к “счастью" через духовное перерождение и обретение дома» (Шевцова, 2003: 40). В основе сюжета находится путешествие двоих незнакомых людей, Нока и Гелли, оказавшихся волею судьбы в одной лодке, которая является для них объединяющим началом, особым топосом. Аодка соединяет не только два противоположных начала, мужское и женское, но и двоих разных людей с прямо противоположными характерами и судьбой, людей, по-разному реагирующих на ситуацию поломки и задержки парохода. Аевушка Гелли не имеет социального опыта, она по-житейски наивна: «Она была худощава, но стройного и здорового сложения, с тонкой талией, тяжелыми темными волосами бронзового оттенка, свежим цветом ясного, простодушного лица и непередаваемым выражением слабого знания жизни» (Грин, 1965: 134). Нок, наоборот, - это человек, прошедший каторгу, узнавший соблазны и горести жизни, которые отразились на его мрачном лице и мировосприятии: «Раздраженное, потемневшее от волнения лицо пассажира показывало, что задержка в пути сильно ошеломила его» (Грин, 1965: 134). Однако в совместном путешествии эти люди и их судьбы меняются коренным образом. Аля художественного мира А. Грина характерен прием оксюморона, которым обусловлена некая подвижность в метафизическом отношении: одно состояние переходит в другое и оборачивается противоположностью, ничто не статично в мире писателя (Аикова, 1996: 113). Но этих героев объединяют даже не столько внешние обстоятельства, как поломка 
парохода, на котором они плыли, необходимость скорого отплытия, одна лодка, доставшаяся им в складчину от пьяного рыбака, сколько внутренний поиск и обретение чего-либо: Гелли стремится к больному отцу, а Нок убегает от преследования властей и ищет покоя. Этот поиск выражен в символе реки, которая выполняет роль сакрального иентра в рассказе. Грин подробно описывает состояния реки, природы, в которые погружены главные герои: «Стемнело, когда эти двое молодых людей тронулись в путь. Только у далекого поворота еще блестела рассыпанным ожерельем стрежь, просвет неба над ней, уступая облачной тьме, медленно потухал, напоминая дремлющий глаз. Блеск стрежи скоро исчез. Крякнула утка; тишину осенил быстрый свист крыльев; а затем ровный, значительный в темноте плеск весел стал единственным одиноким звуком речной ночи» (Грин, 1965: 139; курсив мой - M. А.). Примечательно то, что герои отправляются в путь на закате, когда тьма уже наступает, но свет еще не погас. Здесь можно поставить вопрос об апофатической традиции возникновения света вечернего и невечернего и об особой организации пространства, предполагающей образование места вневременности. Н. В. Брагинская, А. И. Шмаина-Великанова в своей статье «Свет вечерний и свет невечерний» пишут о сосуществовании тьмы и света, когда не борьба важна между ними, а единение, и особенно это ощущается в феномене locus amoenus: «Говоря о переживании света и о первичном опыте, порождающем образ, будет нелишним вспомнить, что в Средиземноморье северного сияния нет, а вот сумерки там не совсем такие, как в северных широтах. Это краткий миг света, когда нет солнца, прекрасное мгновение освещенности и отсутствия тяжкой жары. Краткий миг гармонии: прохлада и неяркий ласковый свет - то, что описывает древнее песнопение “Свете тихий”» (Брагинская, Шмаина-Великанова, 2013: 77-78).

Гелли и Нок не просто путешествуют три дня, что, конечно, тоже символично с позиций сакральной действительности русской волшебной сказки или былины, где герой не ест, не пьет и странствует три дня и три ночи или просит на что-либо отсрочки три дня (например, в былине «Илья Муромец и Калин-царь»; в драме «Царь Максимилиан»), они пускаются в странствие, выражаясь языком онтологии, по мировым водам, и вода здесь обозначает первостихию жизни, принадлежащую горнему миру (Отечественная интеллектуальная культура, 2011: 20). Важно то, что такой апофатический свет сопровождает этих двоих на всем пути, который, стоит также отметить, имеет вектор движения снизу - bверx: «Мы едем снизу, - сказал Нок, - в Зурбагане отличная погода...» (Грин, 1965: 155). Конечно, Нок обманывает охотника Гутана - ведь молодые люди направляются в Зурбаган, что ниже по реке, - но в метафизическом смысле здесь происходит онтологический поворот в движении пути Нока, который начинает свое восхождение по духовной лествиие, и катализатором этого восхождения является зародившаяся любовь к Гелли, осознание вины Ноком. «Ради бога, не плачьте, Гелли! - сказал, сильно страдая, Нок. - Я виноват, я один» (там же: 160). Кроме того, герой обретает в этот момент подлинное имя, преображаясь из беглого Трумвика, человека, вынужденного скрываться под чужим именем, в Нока. Зурбаган, являясь одним из самых частотных авторских локусов (Парамонова, 2008: 285), выполняет здесь функции идеального топоса, своего рода «иного царства», где должно случиться преображение героев.

Но что же ищут на самом деле эти двое, чей сплав по реке не лишен метафизического смысла и онтологического статуса? Нок в спорах с Гелли о любви и женщинах все-таки признается сам себе, что думает только об идеале, а точнее, идеальной возлюбленной: «...о любви только к мечте, верной и нежной спутнице исковеркан- 
ных жизней» (Грин, 1965: 140-141). В этом отношении права Шевцова, указывающая на противоречивость душевного состояния героя: «...под внешним слоем мрачного пессимизма, отчаяния и озлобления скрывается жажда любви и человеческого тепла» (Шевцова, 2003: 40). Гелли тоже мечтала и воспринимала действительность имагинативно, представляя себя героиней романов: «Ей представилось, что она не плывет, а читает о женщине со своим именем в некоей книге, где описываются леса, охоты, опасности» (Грин, 1965: 141). Под имагинацией, вслед за Голосовкером, понимаем высшую образную реальность, которая постигается интуитивно. Итак, молодых людей объединяет особый взгляд на действительность, который можно обозначить как имагинативное видение, выражаясь антропософским языком.

Философ и антропософ начала ХХ в. Р. Штейнер в своих лекциях, которые посещали разные представители творческой интеллигенции Серебряного века, дал представление об особом имагинативном взгляде на действительность, которым был наделен Гете: «...у них отсутствует орган для идеального, и потому они не знают сферу его действия. Посредством того, что у Гете этот орган был особенно развит, он, исходя из своего общего мировоззрения, пришел к глубоким прозрениям в существо живого» (Штейнер, 2011: 134). Среди слушателей был и М. Волошин, встречавшийся с философом в 1906 г. в Париже, где он слушал лекции из «русского цикла» (Пронина, 2005). По замечанию специалистов, на поэта достаточно сильно повлияло антропософское учение (Пинаев, 2009). Волошин являлся ближайшим другом и соседом по Киммерии для Грина. Конечно, можно поставить вопрос и об опосредованном влиянии антропософского учения на писателя, но можно привлечь и еще один ближний контекст, проводя параллели с русской волшебной сказкой, лекции о которой в начале ХХ в. читал в Московском религиозно-философском обществе памяти Вл. Соловьева философ Е. Н. Трубецкой (деятельностью МФРО также интересовались представители творческой интеллигенции начала некалендарного века). Так, в лекции «“Иное царство” и его искатели в русской народной сказке», изданной позднее в виде брошюры, философ высвечивает онтологические и аксиологические основания поиска «иного царства», в который отправляется культурный герой: «Одни удовлетворяют потребности в “новой земле” естественными житейскими способами. Аругие, напротив, преисполняются отвращением ко всему обыденному, житейскому и испытывают непреодолимое влечение к чудесному» (Трубецкой, 1922: 20). Нок уподобляется героям русской волшебной сказки, которые должны спуститься в «иное царство», чтобы добыть сакральные знания, волшебный предмет, вещую невесту (Елеонская, 1994). Параллель с русским фольклором сближает воззрения Грина на смерть, любовь в высшем имагинативном их проявлении с идеалом русской сказки, ее поисками «иного царства», которые направлены на преображение героя, его духовное возрождение в новом качестве.

\section{ЗАКАЮЧЕНИЕ}

Переправа по реке - иниииачионный путь для обоих героев, Гелли, которая должна повзрослеть, и Нока, который должен смягчиться сердцем и поверить в чудо. Река - сакральный иентр в рассказе, она, выражаясь языком онтологии, символизирует мировые воды, поиск «иного царства», в который пускается и русский Иван-дурак, и гриновские влюбленные, чтобы обрести себя и друг друга. Река у Грина не просто художественная деталь, средство переправы для героев - она онтологична, апофатична, поскольку амбивалентна: это и топос смерти, который 
необходимо преодолеть, и этос жизни. Обращение к иномирной эстетике русской волшебной сказки продуктивно в данном случае, поскольку герменевтический анализ образов смерти русского фольклора выводит нас на проблему апофатики художественной культуры. Апофатике трудно дать четкое определение, она всегда ускользает от исследователя, являясь инфиницией, но апофатику художественного космоса культуры можно определить через инобытие художественного текста, его танатологический дискурс.

Сегодняшний день апофатичен и танатологичен, но разобраться в этих явлениях помогает позавчерашний день нашего искусства, который, по тонкому наблюдению А. М. Панченко и И. П. Смирнова, более продуктивен: «В искусстве... всегда присутствует элемент соревнования: соревнуются не только современники между собой; младшее поколение стремится превзойти старшее. При этом ему... бывает легче опереться не на вчерашний, а на позавчерашний день» (Панченко, Смирнов, 1971: 33; курсив мой. - М. А.).

Чему же нас учит Грин? Онтогерменевтический анализ, высвечивание философских вопросов произведения показывают, что рассказ, при всей легкости, сказочности, романтическом настроении, которым пронизаны многие вещи писателя, встраивается в русскую философию жизни - смерти, где последняя в славянском архаическом миропонимании носит временный характер, т. е. инициационный. Грин демонстрирует нам прорыв от тьмы $к$ cbemy, характерный для русского фольклора, иномирной парадигмы волшебной сказки.

\section{СПИСОК АИТЕРАТУРЫ}

Арьес, Ф. (1992) Человек перед лицом смерти / пер. с фр. В. К. Ронина ; общ. ред. С. В. Оболенской ; предисл. А. Я. Гуревича. М. : Прогресс - Прогресс-Академия. 526 с.

Брагинская, Н. В., Шмаина-Великанова, А. И. (2013) Свет вечерний и свет невечерний // Ава венка: Посвящение Ольге Седаковой. Редколлегия: А. В. Марков, Н. В. Аиквинцева, С. М. Панич, И. А. Седакова. М. : Русский фонд содействия образованию и науке. 232 с.

Варава, В. В. (2013) Философская танатология или апофатическая философия? // Научные ведомости Белгородского государственного университета. Серия: Философия. Социология. Право. № 2 (145). Вып. 23. С. 112-117.

Голосовкер, Я. Э. (2012) Имагинативный абсолют. М. : Академический проект. 318 с.

Грачев, В. И. (2019) Культурфеномен апофатики «Аиалектики мифа» А. Ф. Аосева в контексте топохронно-аксиогенной парадигмы культуры [Электронный ресурс] // Культура культуры. № 3. URL: http://cult-cult.ru/cultures-the-phenomenon-of-apophatic-the-dialecticsof-myth-by-a-f-losev (дата обращения: 23.01.2021).

Грин, А. (1965) Сто верст по реке // Грин А. Собрание сочинений : в 6 т. М. : Правда. Т. 2. 494 c. C. $166-204$.

Гуревич, П., Спирова, Э. (2019) Наука в горизонте апофатики // Философская антропокогия. Т. 5. № 1. С. 6-25.

Аикова, Т. Ю. (1996) Рассказы Александра Грина 1920-х годов: поэтика оксюморона : дис. ... канд. филол. наук. Екатеринбург. 245 с.

Аударева, М. А. (2020) Апофатика русского языка и культуры в творчестве Н. С. Гумилева (на примере стихотворения «Жираф») // Наследие веков. № 1. С. 98-104.

Елеонская, Е. Н. (1994) Представление «того света» в сказочной традиции // Сказка, заговор и колдовство в России / Вступ. ст. и сост. $\Lambda$. Н. Виноградовой ; подготовка текста и коммент. А. Н. Виноградовой, Н. А. Пшеницыной. М. : Индрик. 272 с.

Елепова, М. Ю. (2012) Эстетика В. А. Жуковского в апофатическом контексте // Аискуссия. № 4 (22). С. 176-178. 
Аогинова, М. В. (2003) Онтология выразительности в культуре XX века : дис. ... А-ра филос. наук. Саранск. 366 с.

Михайлова, М. Ю. (2017) Семантика невыразимого и средства ее передачи в русском языке : дис. ... А-ра филол. наук. Уфа. 322 с.

Океанский, В. П. (2010) Человек и тотальность: поэтика пространства и ее кризис. Иваново : ШГПУ. 356 с.

Океанский, В. П. (2011) Этосы жизни и смерти у Хомякова и Шопенгауэра (культурологические размышления к обоснованию сопоставления) // Соловьевские исследования. Вып. 3 (31). С. 125-136.

Отечественная интеллектуальная культура: материалы к энциклопедии (моделирующий глоссарий: ключевые имена и понятия) (2011) / сост. и науч. ред. В. П. Океанский. Шуя : Центр кризисологических исследований ФГБОУ ВПО «ШГПУ». 175 с.

Панченко, А. М., Смирнов, И. П. (1971) Метафорические архетипы в русской средневековой словесности и в поэзии начала XX века // TOAP $\Lambda$ XXVI. Аревнерусская литература и русская культура XVIII-XX вв./ отв. ред. А. С. Аихачев. М. : Наука. 380 с. С. 33-49.

Парамонова, Т. А. (2008) Система индивидуально-авторских локусов как механизм создания сверхтекстового единства прозы А. С. Грина (на примере функционирования локусов

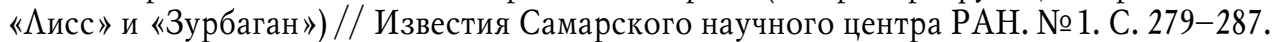

Пинаев, С. М. (2009) «Близкий всем, всему чужой»: Максимилиан Волошин в историкокультурном контексте Серебряного века. М. : ИзА-во РУАН. 343 с.

Пронина, О. (2005) «Руанский собор» Максимилиана Волошина и «Теософия розенкрейцера» Рудольфа Штайнера [Электронный ресурс] // Антропософия. URL: http://www. anthroposophy.ru/index.php?go=Pages\&in=view $\&$ id $=26 \& S N S=$ dfb25a68a04ba8b6e506dde9a 245 03f7 (дата обращения: 31.01.2021).

Татаринова, О. В. (2011) Принципы апофатической поэтики в творчестве А. И. Введенского // Теория и практика общественного развития. № 7. С. 357-359.

Трубецкой, Е. Н. (1922) «Иное царство» и его искатели в русской народной сказке. М. : Тип. Боровичско-Волдайского кустарного и сельско-хозяйств. союзного т-ва. 48 с.

Тульчинский, Г. А. (2020) Уроки А. Платонова в осмыслении рационализации социальной жизни // Наследие. № 1 (16). С. 32-44. DOI: https://doi.org/10.31119/hrtg.2020.1.2.

Хайдеггер, М. (1993) Время и бытие : статьи и выступления / сост., пер., вступ. ст., коммент. и указ. В. В. Бибихина. М. : Республика. 445, [2] с.

Шевцова, Г. И. (2003) Художественное воплощение идеи движения в творчестве А. С. Грина : дис. ... канд. филол. наук. Елец. 165 с.

Штейнер, Р. (2011) Учение о метаморфозе // Штайнер, Р. Мировоззрение Гете : пер. с нем. СПб. : Аеметра. 191 с. С. 86-135.

Шукуров, А. А. (2006) Аискурсивная практика русского авангарда (проблемы апофатики литературно-художественного стиля) // Вестник ИГЭУ. Вып. 1. С. 83-87.

Аата поступления: 27.05.2021 2.

\section{APOPHATIC OF A PLACE OR A SEARCH FOR "ANOTHER KINGDOM" IN A. GRIN'S STORY "ONE HUNDRED VERSTS ALONG THE RIVER” \\ M. A. DUDAREVA \\ PEOPLES' FRIENDSHIP UNIVERSITY OF RUSSIA}

The apophatic of Russian artistic culture is the broadest object of research. Today, the ancient concept "apophatic" radiates into all humanitarian research paradigms. The subject of the article is ways of manifestation of apophatic reality in A. Grin's story "One Hundred Versts Along the River", namely the analysis of the topos of life and death.

The research methodology is reduced to the use of the ontohermeneutic analysis of a literary work, which is aimed at highlighting the philosophical issues of the text, identifying the ethos of life 
and death. The parallel with Russian folklore, the fairy tale, turns out to be productive. Russian verbal culture is characterized by the search for "another kingdom", about which the philosopher E. N. Trubetskoy lectured in the early 20th century in Moscow Religious Society in Memory of Vladimir Solovyov, which included many representatives of the Silver Age. At the typological level, it is also productive to turn to the anthroposophical teachings of R. Steiner, who was well acquainted with the closest friend of the writer M. Voloshin, who met the philosopher in 1906 in Paris. In his works, the German anthroposophist gives an idea of the special imaginative supersensible perception of reality that the main characters of Grin's story possess.

The conclusions obtained in the course of ontohermeneutical analysis can be useful both to cultural scientists, philosophers interested in the issues of the philosophy of culture, and to philologists, since they introduce clarifications into the philosophical concept of life and death in the Russian version of logocentrism. In this regard, this methodology, developed in the Russian school in the works of the philologist and cultural scientist V. P. Okeansky, can be successfully applied to other literary works, in which the thanatological discourse is implemented.

Keywords: apophatic; Russian fairy tale; traditional culture; A. Grin's works; R. Steiner's philosophy; ethos

\section{REFERENCES}

Aries, F. (1992) Chelovek pered litsom smerti / transl. from French by V. K. Ronin; ed. by S. V. Obolenskaya; preface by A. Ya. Gurevich. Moscow, Progress - Progress-Academy. 526 p. (In Russ.).

Braginskaja, N. V. and Shmaina-Velikanova, A. I. (2013) Svet vechernij i svet nevechernij. In: Dva venka: Posvjashbenie Ol'ge Sedakovoj/ ed. board: A. V. Markov, N. V. Likvintseva, S. M. Panich and I. A. Sedakova. Moscow, Russian Foundation for the Promotion of Education and Science. 232 p. (In Russ.).

Varava, V. V. (2013) Filosofskaja tanatologija ili apofaticheskaja filosofija? Nauchnye vedomosti Belgorodskogo gosudarstvennogo universiteta. Serija: Filosofija. Sociologija. Pravo, no. 2 (145), iss. 23, pp. 112-117. (In Russ.).

Golosovker, Ja. Je. (2012) Imaginativnyj absoljut. Moscow, Akademicheskij proekt. 318 p. (In Russ.).

Grachev, V. I. (2019) Kul'turfenomen apofatiki «Dialektiki mifa» A. F. Loseva v kontekste topohronno-aksiogennoj paradigmy kul'tury Kul' tura kul' tury, no. 3 [online] Available at: http://cultcult.ru/cultures-the-phenomenon-of-apophatic-the-dialectics-of-myth-by-a-f-losev/ (accessed: 23.01.2021). (In Russ.).

Grin, A. (1980) Sto verst po reke. In: Grin, A. Sobranie socbinenij: in 6 vols. Moscow, Pravda. Vol. 2. 494 p. Pp. 166-204. (In Russ.).

Gurevich, P. and Spirova, Je. (2019) Nauka v gorizonte apofatiki. Filosofskaja antropologija, no. 1, vol. 5, pp. 6-25. (In Russ.).

Dikova, T. Ju. (1996) Rasskazy Aleksandra Grina 1920-b godov: pojetika oksjumorona. Dis. ... Cand. of Philology. Ekaterinburg. 245 p. (In Russ.).

Dudareva, M. A. (2020) Apofatika russkogo jazyka i kul'tury v tvorchestve N. S. Gumileva (na primere stihotvorenija Zhiraf). Nasledie vekov, no. 1, pp. 98-104. (In Russ.).

Eleonskaja, E. N. (1994) Predstavlenie "togo sveta” v skazochnoj tradicii. Skazka, zagovor $i$ koldovstvo $v$ Rossii / intr. article and comp. by L. N. Vinogradova ; preparation of the text and comments by L. N. Vinogradova and N. A. Pshenitsyna. Moscow, Indrik. 272 s. (In Russ.).

Elepova, M. Ju. (2012) Jestetika V. A. Zhukovskogo v apofaticheskom kontekste. Diskussija, no. 4 (22), pp. 176-178. (In Russ.).

Loginova, M. V. (2003) Ontologiia vyrazitel' nosti v kul'ture XX veka. Dis. ... Dr. of Philosophy. Saransk. 366 p. (In Russ.).

Mikhailova, M. Yu. (2017) Semantika nevyrazimogo $i$ sredstva ee peredachi v russkom iazyke. Dis. ... Dr. of Philology. Ufa. 322 p. (In Russ.). 
Okeansky, V. P. (2010) Chelovek i total' nost': poetika prostranstva i ee krizis. Ivanovo, Shuisky State Pedagogical University named after D. A. Furmanov. 356 p.

Okeanskij, V. P. (2011) Jetosy zhizni i smerti u Homjakova i Shopengaujera (kul'turologicheskie razmyshlenija k obosnovaniju sopostavlenija). Solov' evskie issledovanija, iss. 3 (31), pp. 125-136. (In Russ.).

Otechestvennaja intellektual' naja kul'tura : materialy $k$ jenciklopedii (modelirujushbij glossarij: kljuchevye imena i ponjatija) (2011) / comp. and ed. by V. P. Okeansky. Shuja: Center for Crisis Research of Shuisky State Pedagogical University named after D. A. Furmanov. 175 p. (In Russ.).

Panchenko, A. M. and Smirnov, I. P. (1971) Metaforicheskie arhetipy v russkoj srednevekovoj slovesnosti i v pojezii nachala XX veka. TODRL XXVI. Drevnerusskaja literatura i russkaja kul' tura XVIII-XX vv./ ed. by D. S. Likhachev. Moscow, Nauka. 380 p. (In Russ.).

Paramonova, T. A. (2008) Sistema individual'no avtorskih lokusov kak mehanizm sozdanija sverhtekstovogo edinstva prozy A. S. Grina (na primere funkcionirovanija lokusov «Liss» i «Zurbagan»). Izvestija Samarskogo nauchnogo centra RAN, no. 1, pp. 279-287. (In Russ.).

Pinaev, S. M. (2009) «Blizki vsem, vsemu chuzhoj»: Maksimilian Voloshin v istoriko-kul'turnom kontekste Serebrjanogo veka. Moscow, Peoples' Friendship University of Russia. 343 p. (In Russ.).

Pronina, O. (2005) «Ruanskij sobor» Maksimiliana Voloshina i «Teosofija rozenkrejcera» Rudol'fa Shtajnera. Antbroposopby [online] Available at: http://www.anthroposophy.ru/ index.php?go=Pages\&in=view\&id=26\&SNS=dfb25a68a04ba8b6e506dde9a24503f7 (accessed: 31.01.2021). (In Russ.).

Tatarinova, O. V. (2011) Principy apofaticheskoj pojetiki v tvorchestve A. I. Vvedenskogo. Teorija i praktika obshbestvennogo razvitija, no. 7, pp. 357-359. (In Russ.).

Trubeckoj, E. N. (1922) "Inoe carstvo» $i$ ego iskateli v russkoj narodnoj skazke. Moscow, Printing house of the Borovichi-Valdai handicraft and agricultural Union Association. 48 p. (In Russ.).

Tulchinskii, G. L. (2020) Uroki A. Platonova v osmyslenii racionalizacii social'noj zhizni. Nasledie, no. 1 (16), pp. 32-44. (In Russ.).

Hajdegger, M. (1993) Vremya i bytie : stat' i i vystupleniya / comp., transl., intr. article, indexes by V. V. Bibihin. Moscow, Respublika. 445, [2] p. (In Russ.).

Shevcova, G. I. (2003) Hudozhestvennoe voploshbenie idei dvizhenija v tvorchestve A. S. Grina. Dis. ... Cand. of Philology. Elec. 165 p. (In Russ.).

Shtejner, R. (2011) Uchenie o metamorfoze. In: Shtejner, R. Mirovozzrenie Gete / transl. from German. St. Petersburg, Demetra. 191 p. Pp. 86-135. (In Russ.).

Shukurov, D. L. (2006) Diskursivnaja praktika russkogo avangarda (problemy apofatiki literaturno-hudozhestvennogo stilja). Vestnik Ivanovskogo gosudarstvennogo energeticheskogo universiteta, iss. 1, pp. 83-87. (In Russ.).

Submission date: 27.05 .2021$.

Аударева Марианна Андреевна - кандидат филологических наук, доцент, Российский ун-т дружбы народов. Адрес: 117198 , Россия, г. Москва, ул. Миклухо-Маклая, А. 6. Тел.: +7 (495) 787-38-03. Эx. aspec: marianna.galieva@yandex.ru

Dudareva Marianna Andreyevna, Candidate in Philology, Associate Professor, Peoples' Friendship University of Russia. Postal address: 6, Miklukho-Maklaya St., Moscow, Russian Federation, 117198. Tel.: +7 (495) 787-38-03. E-mail: marianna.galieva@yandex.ru 